\title{
DEGRADABILIDADE DA PROTEINA E DESDOBRAMENTO DA MIMOSINA DA LeUcaena Leucocephala (LAM) DE WITH NO RÚMEN DE BÚFALOS SOB DIETAS COM DIFERENTES NÍVEIS DE PROTEINAS.
}

\author{
PROTEIN DEBRADABILITY AND TRANSFORMATION OF MIIMOSINE FROM Leucaena \\ leucocephala (LAM) DE WITH IN THE RUMEN OF BUFFALOES UNDER DIETS WITH DIFFERENT \\ PROTEIN LEVELS.
}

Raul FRANZOLIN NETO'; Pedro de ANDRADE; ; Dario OCAMPOS

\begin{abstract}
RESUMO
A técnica de sacos de náilon suspensos no rúmen foi utilizada para estudar a degradabilidade da protcína bruta $\mathrm{c}$ do desdobramento da mimosina da Leucaena le ucocephala $\mathrm{cm}$ búfalos submetidos a um experimento cm quadrado latino $(4 \times 4)$ com diferentes nívcis de protcína bruta na ração $(8,7 ; 10,5$; 12,5 c 14,9\% na MS). As raçðcs não promoveram diferençassignificativas $(\mathrm{P}>0,01)$ na degradabilidade ruminal da protcína bruta da leucacna, que variou entre $30,92 \%$ c $71,70 \% \mathrm{~cm} 3 \mathrm{c} 48$ horas de suspensão no rúmen, respectivamente. Houve uma lenta degradação ruminal da protcína $c$ um acentuado desdobramento da mimosina nas amostras de leucacna colocadas dentro dos sacos de náilon no rúmen de búfalos.
\end{abstract}

UNITERMOS: Leucaena; Protcínas; Mimosina; Rúmcn, digcslibilidadc; Búfalos

\section{INTRODUÇÃO}

A Leucaena leucocephala é uma leguminosa arbustiva dc origem tropical com grande potencial de uso como planta forragcira na alimentaçāo animal (JONES ${ }^{11}$, 1979; FRANZOLIN NETO', 1984).

A suplementação alimentar com leucacna tem produzido aumentos no ganho $\mathrm{cm}$ peso de bovinos (SOBALE ct al. $.^{18}, 1978$ ) c na produção dc leitc (FLORES ct al. $\left.{ }^{3}, 1979\right)$. Mclhora na produtividade animal com alimentação de lcucacna pode cstar associada ao clcvado tcor de protcína bruta da planta e também cm funçăo da solubilidade da protcína afctando a taxa dc digestão nitrogenada no rúmen (AII; STOBBS', 1980). Entretanto o potencial total da lcucacna como fonte protéica na nutrição animal $\mathfrak{c}$ limitado pela prescnça de um aminoácido não protéico, tóxico, existente $\mathrm{cm}$ todas as partes da planta, denominado mimosina, que sofre desdobramento pelos microrganismos no rúmen produzindo 3,4-DHP (Dihidroxipiridina) c outros compostos (FRANZOLIN NETO; VELLOSO', 1987). Vários pesquisadores têm trabalhado procurando novos conhecimentos sobrc o metabolismo da mimosina nos animais, na tentativa de se descobrir soluçōes viáveis para a ncutralização dos cf́citos tóxicos verificados nos animais devido à ingestăo da mimosina (KUDO ct al. ${ }^{12}, 1984$; QUIRK ct al." ${ }^{17}$ 1988; FRANZOLIN NETO; VELLOSO', 1986).

A técnica de sacos de náilon suspensos no rúmen de animais fistulados por determinados períodos de tempo tem sido utilizada para a determinação da degradaçăo de nutrientes pelos microrganismos no rúmen como avaliação da forma de disponibilidade de nutrientes pelos animais (ORSKOV et al. ${ }^{16}, 1980$; NOCEK $\left.{ }^{13}, 1988\right)$.

Estc trabalho descreve uma avaliação da degradabilidade ruminal da proteína da lcucacna c do desulobramento da mimosina $\mathrm{cm}$ búfalos alimentados com difcrentes níveis $\mathrm{dc}$ protcina bruta na ração.

\section{MATERIAL E MÉTODO}

Quatro búfalos (Bubalus bubalis L.), machos castrados, $\mathrm{scm}$ raça definida, apresentando peso médio de $430 \mathrm{~kg}$ c fístulas no rúmen, foram utilizados num experimento $\mathrm{cm}$ quadrado latino (Q.L. $4 \times 4$ ). Os tratamentos consistiram de quatro raçð̄es formuladas com niveis crescentes de proteína bruta na matćria seca: $8,7 \% ; 10,5 \% ; 12,3 \%$ c $14,9 \%$. As raçð̃es foram compostas de capim sempre verde (Panicum maximum var gongyloides) picado como volumoso ( $70 \% \mathrm{MS}$ ) c com milho c soja tostada $\mathrm{cm}$ grãos como concentrado (30\% MS). Os animais foram alimentados duas vezcs ao dia c receberam cerca de $50 \mathrm{~g}$ de uma mistura completa comercial de sal mincral. As composiçð̄es bromatológicas das raçð̄es podem scr obscrvadas no Quad. 1.

Nos últimos dois dias de cada período do Q.L., foram colocados suspensos no rúmen de cada búfalo, 5 sacos de náilon contendo leucacna desidratada (Leucaena leucocephala cv Peru), sendo retirados após 3, 6, 12, 24 c 48 horas, conforme técnica descrita por ORSKOV et al..$^{16}$ (1980). A leucacna foi colhida manualmente e desidratada $\mathrm{cm}$ cstufa de circulação forçada de ar a $65^{\circ} \mathrm{C}$ durante 72 horas (pré-sccagcm), sendo depois moída $\mathrm{cm}$ moinho com pencira de $1,0 \mathrm{~mm}$. A composição bromatológica da leucacna utilizada encontra-se aprescntada no Quad. 1. Os sacos de náilon foram preparados com tccido de pára-quedas c cortados na forma retangular $(7,5 \mathrm{x}$ $17,0 \mathrm{~cm}$ ), colocando-sc aproximadamentc $7,0 \mathrm{~g} \mathrm{de}$ lcucacna $\mathrm{cm}$ cada saco. Após a retirada dos saquinhos do rúmen, cles cram lavados um a um $\mathrm{cm}$ água corrente atć que a água

1-Professor Doutor - Faculdade de Medicina Vecrinánia c Zootconia da USP

2-Professor Titular - Faculdade de Ciências Agrárias c Velerinánias da UNIQSP - Campus de Jaboticabal

3-Proíessor Associado - Faculdade de Medicina Veterinária c Zootecnia da USP 
NETO, R.F.; ANDRADE, P.; OCAMPOS, D. Degradabilidade da protcína e desdobramento da mimosina da Leucaena Leucocephala (Lam) de with no rúmem de búfalos sob dietas com diferentes níveis de protcína. Braz. J. vet. Res. anim. Sct., São Paulo, v.29, p. 375-377. 1992. Suplemento.

QUADRO 1

Composiçöes bromaıológicas das rą̧öes e da leucacna utilizadas (\% na MS)

\begin{tabular}{|c|c|c|c|c|c|}
\hline \multirow{2}{*}{ Nutrientes } & \multicolumn{4}{|c|}{ Rações } & \multirow[t]{2}{*}{ Leucacna } \\
\hline & $\Lambda$ & B & C & D & \\
\hline Protcína bruta & 8.73 & 10,51 & 12,33 & 14,90 & 25,44 \\
\hline Fibra bruta & 32.24 & 32,88 & 33,31 & 33,56 & 15,93 \\
\hline Éxtrato ctéreo & 5,12 & 5,67 & 6,24 & 6,89 & 4,62 \\
\hline $\begin{array}{l}\text { Extrativo não } \\
\text { nitrogenado } \\
\text { Cinzas }\end{array}$ & $\begin{array}{r}49,10 \\
4,80\end{array}$ & $\begin{array}{r}45,93 \\
5,00\end{array}$ & $\begin{array}{r}42,94 \\
5,18\end{array}$ & $\begin{array}{r}39.90 \\
5.34\end{array}$ & $\begin{array}{r}45,11 \\
7,47\end{array}$ \\
\hline
\end{tabular}

Os métodos analíticos usados foram: Protcína bruta-kjeldahl; fibra bruta A.O.A.C. (1970), extrato ctérco - Soxhlet; cinzas - A.O.A.C. (1970).

cscorresse limpida do interior dos mesmos, sendo posteriormente submetidos à pré-sccagcm c analisados para matéria scca total, cinzas c protcína bruta.

As concentraçős de mimosina nas amostras de leucacna $\mathrm{c}$ nas suspensas no rúmen foram delerminadas segundo adaptaç̃ô do método colorimétrico descrito por MATSUMOTO; SHERMAN $^{14}$ (1951) c ALLISON ct al. ${ }^{2}$ (1990). A digcstăo das amostras foi feita com $\mathrm{HCl} 0,1 \mathrm{~N}$ durantc uma hora a frio, $\mathrm{scm}$ agitação. Para determinaç̃o da curva padrão, mimosina pura (Sigma Chemical Co.) foi dissolvida $\mathrm{cm} \mathrm{HCl} 0,1 \mathrm{~N} \mathrm{c} \mathrm{o}$ rcagente de clorcto férrico $\left(\mathrm{FcCl}_{3}, 6 \mathrm{H}_{2} 0\right)$ utilizado foi preparado como uma soluçāo a $0,5 \%$ lambém $\mathrm{cm} \mathrm{HCl} 0,1 \mathrm{~N}$. As lcituras das amostras foram rcalizadas $\mathrm{cm}$ espectrofotômetro (Bcckman, DU-70) $\mathrm{cm} 535 \mathrm{~nm}$.

\section{RFSULTADOS E DISCUSSĀO}

Não houve diferenças significativas $(\mathrm{P}>0,01)$ nas degradabilidades ruminal da matćria soca, matćria orgânica c protcína bruta da Jcucacna entre os tratamentos, cm todos os tempos de incubação cstudados. Os valores médios obtidos podem ser obscrvados no Quad. 2. Assim, a degradabilidadc da MS, MO c PB da lcucacna no nímen de búfalos nāo foi influcnciada pelo nivel de protcína bruta na dicta dos animais. FARIA c HUBER ${ }^{4}$ (1984) não obscrvaram cfcitos significativos do nívcl de protcína bruta na ração $(8,1 ; 11,3$ c $13,3 \%)$ sobre a degradabilidaxdc numinal da matćria soca de feno de alfafa $\mathrm{c}$ de gramincas $\mathrm{cm}$ bovinos. FRANZOLIN NETO' (1990) também não verificous o cfcito do tcor de prolcína na raço sobre a degradabilidade ruminal da MS, MO, PB c FDN do capim scmpre verde $\mathrm{cm}$ búfalos.

AIl c STOBBS' (1980) não vcrificaram intcraçōes cntre diferentes diclas $\mathrm{cm}$ novilhos sob pastejo de Panicum maximum $\mathrm{c}$ de lcucacna sobre a taxa de desaparceimento da protcína de amostras dc Panicum maximum, Leucaena kucocephala c Desmodium intortum $\mathrm{cm}$ sacos de náilon do rúmen. Porém, variaģðes accntuadas na dicta de ruminantcs, principalmentc $\mathrm{cm}$ função da relax̧ão volumoso: concentrado $\mathrm{c}$ nível de ingestão de matéria soca, promovem diferenças na degradabilidade de nutrientes devido a variacrocs nas taxas de "umover" ruminal (CHURCH", 1974; VARGA; PRIGGE' ${ }^{20}, 1982$ ).

As taxas de degradabilidade da matćria scca c protcínas foram scmelhantes, cnurctanto, não houvc diferença significativa na degradabilidade da protcína bruta até 12 horas no rúmen. AII $\mathrm{c}$ STOBBS' (1980) obscrvaram valores mais baixos para o desaparocimento da protcína bruta da leucacna $\mathrm{cm}$ sacos de náilon no rúmen de bovinos após 12 horas de suspensão $(16,1 \%)$ e também atc 72 horas $(63,4 \%)$. Apesar disso, a lenta degradação numinal da protcína verificada principalmente até 12 horas (Tab. 1), permite corroborar com a obscrvaçào feita por csses pesquisadores de que o tempo prolongado de degradação ruminal da protcína da lcucacna pode scr de considcrável importância prática, já que leguminosas apresentam menor tempo de retenção no rúmen que gramíncas (THORNTAN; MINSON ${ }^{19}, 1973$ ) c portanto, maior quantidade de protcínas não degradávcis no rúmen poderá ser hidrolisada e absorvida no intestino delgado com maior benclício para produçæo animal.

\section{TABELA}

Degradabilidade média da matéria seca (DRMS), matéria orgânica (DRMO) c proténa bruta (DRPB) da lcucacra cm diversos tempos de suspensão dos sacos de náilon no númen. Pirassununga, 1991.

\begin{tabular}{cccc}
\hline Iloras no rúmen & DRMS (\%) & DRMO (\%) & DRPB (\%) \\
\hline 3 & $37,49 \mathrm{a}$ & $34,88 \mathrm{a}$ & $30,92 \mathrm{a}$ \\
6 & $39,67 \mathrm{a}$ & $36,82 \mathrm{a}$ & $31,87 \mathrm{a}$ \\
12 & $43,10 \mathrm{~b}$ & $40,33 \mathrm{~b}$ & $34,48 \mathrm{a}$ \\
24 & $57,41 \mathrm{c}$ & $55,24 \mathrm{c}$ & $50,47 \mathrm{~b}$ \\
48 & $71.77 \mathrm{~d}$ & $70,63 \mathrm{~d}$ & $71,70 \mathrm{c}$
\end{tabular}

Letras distintas na mesma coluna diferem entre si ao nível de 5\% de significância pelo teste de Tukcy.

Houve cvidência de um rápido desdobramento da mimosina nas amostras de lcucacna colocadas $\mathrm{cm}$ sacos de náilon no rúmen de búfalos (Tab. 2). Após 3 horas de permanência no rúmen o tcor $\mathrm{dc}$ mimosina diminuiu drasticamentc de $1,2 \%$ na MS para $0,15 \%$ na MS; a partir daí, os teores de mimosina diminuíram gradativamentc alé atingir o valor de $0,02 \% \mathrm{MS}$ com 48 horas de suspensāo. Houve provavelmente uma marcada ação no rủmen dos microrganismos que atuam no desdobramento da mimosina, transformando-a cm DHP c/ou outros compostos conforme citado por FRANZOLIN NETO; VELLOSO $^{9}$ (1987) c HAMMOND ct al. ${ }^{10}$ (1988). Existem vários fatores que influcm no desdobramento da mimosina, particularmente a temperatura (LOWRY et al. ${ }^{13}, 1983$ ), porém, no presentc trabalho, tanto as amostras de lcucacna retiradas dos sacos de náilon suspensos no rúmen, como as amostras da lcucacna fresca, foram pré-sccadas $\mathrm{cm}$ estufas dc circulação forçada dc ar à $65^{\circ} \mathrm{C}$ por 72 horas.

\section{TABELA 2}

Desdobramento da mimosina nos diversos tempos de permanência das amostras de leucacna no rúmen de búlalos. P'irassununga, 1991.

\begin{tabular}{ccc}
\hline Huras no númen & Mimosina (\% MS) & Desdobramento (\%) \\
\hline 0 & 1,20 & 0,0 \\
3 & $0,15 \mathrm{a}$ & 87,5 \\
6 & $0,11 \mathrm{ab}$ & 90,8 \\
12 & $0,11 \mathrm{ab}$ & 90,8 \\
24 & $0,07 \mathrm{ab}$ & 94,2 \\
48 & $0,02 \mathrm{~b}$ & 98,3 \\
\hline
\end{tabular}

Letras distintas diferem entre si ao nível de $5 \%$ de significância pelo Teste de Tukcy.

\section{CONCLUSÖES}

1. Niveis crescentes de matéria bruta na raçāo $(8,73 ; 10,5 \mathrm{I}$; $12,33 \mathrm{c} 14,90 \%)$ não promovcram diferenças significativas $(p>0,01)$ na degradabilidade ruminal da protcína bruta da Leucaena leucocephala $\mathrm{cm}$ búfalos.

2. Houve uma degradação lenta da proteína bruta principalmente durante as 12 primeiras horas de suspensão da leucacna no rúmen. 
NETO, R.F.; ANDRADE, P.; OCAMPOS, D. Degradabilidade da proceína e desdobramento da mimosina da Leucaena Leucocephala (Lam) de with no rímem de buffalos sob dietas com diferentes níveis de proteína. Braz J. vet. Res. anim. Sa., Såo Paulo, v.29, p. 375-377, 1992. Suplemento.

3. Houve cvidência de um accntuado desdobramento da mimosina dentro de sacos de náilon suspensos no rúmen de búfalos.

\section{SUMMARY}

The ruminal suspended nylon bags technique was used to study the degradability of crude protcin and disintegration of minosin of Leucaena leucocephala in water buffalocs. The experimental desing was in a $4 \times 4$ Latin squarc, with variable levels of crude protcin $(8.8,10,5,12,5$, and $14.9 \%$ of dry matter). The dicts did not cause significant differences on the ruminal degradation of crude protcin of Lcucacna ( $P>0.01$ ), that ranged from 30.92 to $71.70 \%$ in, respectively, 3 or 48 hours of ruminal exposition. There was observed a clow ruminal protcin degradation and a strong desingration of mimosin on the samples of Leucaena exposed in nylon bags to the rumen of water buffalocs.

UNITERMS: Leucaena; Protcins; Mimosinc; Rumen, digcstibility; Buffalo

\section{REFERÊNCIAS BIBLIOGRÁFICAS}

01 -AII, T.; STOBBS, T.H. Solubility of the protein of tropical pasture species and the rate of its digestion in the rumen Anim. Feed Sci. Techn., v. 5, p.183-92, 1980.

02-ALLISON, M. J.; HAMMOND, A. C.; JONES, R. J. Delection of ruminal bacteria that degrade toxic dihydroxypyridine compounds produced from mimosine A ppl. Env. Microbid., v. 56, p. $590-4,1990$.

03-CHURCH, D. C. Fisiolngla digestiva Y nutrición de los ruminantes. Acribia, Zaragoza, 1974. v. 1.

04-FARIA. V. P.; HUBER, J. T. Influence of dictary protein and energy on disappearence of ctry matter from different forage types from dracon bags suspended in the rumen. J. anim. Sci., v. 59, p. 246-52, 1984.

05-FLORES, J. F.; STOBBS, T. H.; MINSON, D. J. The influence of the legume Leucaena leucocephala and formal-cascin on the production and composition of milk from grazing cows. J. agric. Sci., v. 92, p. 351-7, 1979.

06-FRANZOLINNETO, R. Valor nutritivo e toxicldade da Leucaena leucocephula (Lam.) de wit determinados em ovinos. Såo Paulo, 1984. Disscrtação (Mcstrado) - Faculdade de Medicina Veterinária e Zootecnia, Universidade de São Paulo.

07-FRANZOLIN NETO, R. Efeitos de raçōes com diferentes nivels de nitrogenjo degradável no rúmen sobre os desaparecimentos in situ da matéria seca, matéria orgânica, proteína bruta e fibra em detergente neutro em búfalos.
Jaboticabal, 1990. Tese (Doutorado) - Faculdade de Ciências Agrárias e Veterinárias. Universidade Estadual Paulista.

08-FRANZOLIN NETO, R.; VELLOSO, L. Leucaena leucocephala (Lam.) de wit em rações para ovinos. 2. Toxicidade Rev. Soc. Bras. Zootec, v. 15, p. 415-24, 1986.

09-FRANZOLIN NETO, R.; VELLOSO, L. Aspectos tóxicos da Leucaena leucocephala (Lam.) de wit. Comum. Clent. Fac. Med. Vet. Zootec. Univ. S. Paulo, v. 11, p. 37-47, 1987.

10-HAMMOND, A. C.; ALLISON, M. J.; WILLIAMS, M. J.; PRINE, G. M.; BATES, D. B.; ADAMS, M.S. Ruminal degradation of toxic constitucnts in Leucacna and potential as a forage legume. In: INTERNATIONAL CONFERENCE ON LIVESTOCK IN THE TROPICS. Florida, 1988. Proceedings. p. A-27-A-35.

11-JONES, R.J. El valor de Leucaena le ucocephala como picnso para ruminantes en los trópicos. Rev. mund. Zootec., v. 31, p. 1323, 1979.

12-KUDO, H.; CHENG, K. J.; MAJAK, W; HALL, J. W.; COSTERTON, J. W. Degradation of mimosine in rumen fluid from cattle and shecp in Canada. Canad. J. anim. Scl., v. 64, p. 937-42, 1984.

13-LOWRY, J. B.; MARYANTO; TANGENDJAJA, B. Autolysis of mimosinc L 3-hydroxy 4-1 (H) pyridonc in groen tissues of Leucaena kucocephala. J. ScL. Food Agric., v. 34, p. 529-33, 1983.

14-MATSUMOTO, H.; SHERMAN, G. D. A rapid colorimetric method for the determination of mimosine. Arch. Blochem. Blophys., v.33. p. 195-200, 1951.

15-NOCEK. J.E. In situ and other methods to estimate ruminal protein and encrgy digestibility: arevicw.J. Duiry Scl., v.71,p. 2051-69, 1988.

16-ORSKOV, E. R.; Deb HOVELL, F. D.; MOULD, F. Uso de la tecnica de la bolsa de nylon para valuàcion de los alimentos. Prod. anim. Trop. , v. 5, p.213-33, 1980.

17-QUIRK, M. F.; BUSHELL, J. J.; JONES, R. J.; MEGARRITY, R. G.; BUTLER, K. L. Live-weight gains on leucacna and native grass pastures after dosing cattle with rumen bacteria capable of degrading DHP, a ruminal metabolite from leucacna. J. Agric. Sci.. Camb., v. 111, p. 165-70, 1988.

18-SOBALE, B. N.; KHARAT, S.T.; PRASAD, V. L.; JOSHI, A. L.; RANGNEKAR, D. V.; DESHMUKH, S. S. Nutritive value of Leucaena leucocephala for growing bull calves. Trop. Anim. Hith. Prod., v. 10, p. 237-41, 1978.

19-THORNTON, R. F.; MINSON, D. J. The relationship belween apparent retention time in the rumen. voluntary intake and apparent digestibility of legume and grass diets in sheep. Aust. J. agric. Res., v. 24, p. 889-98, 1973.

20-VARGA, G. A.; PRIGGE, E. C. Influence of forage species and level of intake on ruminal tumover rates. J. anim. Scl., v. 55. p.1498 - 504, 1982.

Recebido para publicaçăo em 21/11/1991 Aprovado para publicação cm 16/06/1992 